\title{
Liquidity Dynamics of Indian Stock Market in Financial Shocks: Extreme Value Theory
}

\author{
Sumit Kumar Jha, Mousumi Bhattacharya, Sharad Nath Bhattacharya \\ Department of Finance, Indian Institute of Management, Shillong, India \\ Email: sumitsony@gmail.com,msb@iimshillong.ac.in, snb@iimshillong.ac.in
}

How to cite this paper: Jha, S.K., Bhattacharya, M. and Bhattacharya, S.N. (2018) Liquidity Dynamics of Indian Stock Market in Financial Shocks: Extreme Value Theory. Theoretical Economics Letters, 8, 3062-3072. https://doi.org/10.4236/tel.2018.814190

Received: May 22, 2018

Accepted: October 21, 2018

Published: October 24, 2018

Copyright $\odot 2018$ by authors and Scientific Research Publishing Inc. This work is licensed under the Creative Commons Attribution International License (CC BY 4.0).

http://creativecommons.org/licenses/by/4.0/

\begin{abstract}
The paper tries to capture the liquidity dynamics in the case of extreme events such a soil price shock and the sub-prime crisis by considering trading probability (TP), market efficiency coefficient (MEC) and total volume (TV) as liquidity measures in the Indian context. Using extreme value theory (EVT), the results provide evidence for the presence of significant liquidity risk in the Indian market. The results reveal a low observed value of TP during the sub-prime financial crisis. Based on the analyses of MEC, it can be concluded that despite the presence of liquidity risk, the Indian market is quite resilient even in extreme conditions. It can also be concluded that Indian market is risky for speculators; however for long-term investment liquidity risk is lower for BSE 500 indexed shares. The study has implications in exploring how market participants rebalance their portfolios in response to liquidity uncertainty.
\end{abstract}

\section{Keywords}

Stock Market Liquidity, EVT, Trading Probability, Market Efficiency

Coefficient

\section{Introduction}

General economic theory tells us that well-functioning and frictionless markets bring outcomes that finally benefits consumers [1]. As an influencer of trading costs, market liquidity, therefore, affects the ability of the corporates, funds, dealers and other market participants in investment activity, hedging and market making. Liquidity can be defined as the financial measurement that describes the degree to which an asset or security can be quickly bought or sold in the market without affecting the asset's price. Brunnermeire and Pedersen [2] define asset's market liquidity as "the ease of a trade" and linked it to trader's funding 
liquidity which is the ease with which traders get the funding.

Various study based on the dimension of liquidity shows the benefits of the presence of liquidity in the financial market. Liquidity in stock markets also has a relationship with rates of economic growth [3]. There exists a positive relationship between liquidity and asset returns [4] [5].

Liquidity conditions can differ significantly across the asset classes, even in normal times. A number of asset classes (Stocks, Bonds and Real estate etc.) show time-series and cross-section variation in liquidity. This variation matters to market participants who worry about the cost of trading into or out of the desired position in a short period of time [6]. Understanding the dynamic nature of liquidity is important for multiple reasons. Some of these reasons are: market liquidity risk might be a factor of assets pricing [4], market liquidity can influence trader's behavior [5], and the liquid market may offer efficient trading [7] and the effectiveness of monetary policy also depends on liquidity conditions in financial markets [8].

The sub-prime crisis has shown that liquidity of the global markets can plunge suddenly and the market liquidity worsens when the participants are eager to trade. This illiquidity and consequent risk often flares up volatility, spreads across asset classes through the globe with various assets showing increased correlations between them. This connection between extreme events and illiquidity challenges the financial system with the possibility of increased systematic risk and spreads and tightened risk management practices. It could lead to significant fluctuations in asset prices. In this paper, we investigate the liquidity dynamics during turbulent conditions in Indian stock market using extreme value theory (EVT) which implicitly considers unseen and un-fathomable shocks like adverse movements of oil price and global events like the sub-prime crisis.

\section{Literature Review}

Chordia and Subrahmanyam [5] produce empirical evidence for statistically significant and negative effect of liquidity on risk-adjusted returns by employing the turnover rate and the trading volume as a proxy for market liquidity. In the same line, Pastor and Stambaugh [9] document that more volatile liquidity leads to lower expected returns from stocks. Marshall and Young [10] find a similar result for Australian stock market with a turnover rate. However, Martinez, Nieto, Rubio, and Tapia [11] could not find any significant empirical evidence for the link between returns and liquidity when bid-ask spread is used for liquidity proxy in Spanish stock market. Going further, Chordia and Subrahmanyam [8] explain how market efficiency and liquidity are linked. Additionally, in view of institutional features elucidated by Masulis and Shivakumar [12], features such as opening price setting, limit orders or other trading rules play an important role in the relationship of liquidity with market efficiency. Stoll [13] attributes electronic trading for the improvements of the market efficiency by reducing the cost of liquidity. In the case of emerging market, work on liquidity 
dynamics is limited and results are contradictory. Lesmond [14] documents the significant bid-ask spread of the emerging market and attributes substantial returns to liquidity risk premium in volatile emerging markets. But, Jun, Marathe, and Shwaky [15] conclude that emerging markets with higher liquidity have higher stock valuations. Additionally, contradictory evidence for a link between liquidity and returns has been documented with an inadequate economic explanation [15] [16].

This provides a scope for researchers to study "liquidity dynamics in emerging markets like India" because of following important reasons: poor liquidity prevents FIIs from investing in emerging markets, liquidity effects may be particularly strong, namely in emerging markets as shown by Bekaert, Harvey and Lundblad [17], common determinants in liquidity may not be valid in emerging market economies and it is not fully understood why this phenomenon is observed [18]. Additionally, emerging markets are highly dependent on global liquidity. A liquidity stress event that originates from advanced economies is likely to affect emerging markets [19]. Hence, the following research gap has been identified: the majority of studies have been done only for developed financial markets, contradictory evidence and no major work with attention to an extreme liquidity condition in Indian stock market. Therefore, our study on liquidity dynamics focusing on the extreme case (such as liquidity evaporation), adds to the sparse extant literature.

\section{Data and Methodology}

The study focuses on a major stock exchange of India-Bombay stock exchange (BSE) and considers composite indices BSE 500 for the time period from July 2002 to Feb 2016. The idea is to consider a well-diversified index from the exchange so that it consists of companies of different market capitalization and categories. Our data covers the pre-subprime and the post-subprime crisis period, which is apt for studying the extreme change in liquidity during that period.

In this paper, to gauge the robustness of the effect of liquidity on returns, we consider trading probability (TP), market efficiency coefficient (MEC) and natural log of trading value (TV) as liquidity measures. We consider the trading probability (TP) as an additional measure of liquidity, which is calculated as Probability equals $1 /(1+$ the number of non-trading days in a month) following Narayan and Zheng [16]. Along with the ease of trade, this measure also captures the speed dimension of liquidity. The study also considers MEC which measures the impact of execution costs on price volatility. MEC is calculated as MEC $=$ Long Term Variance $/(\mathrm{T} \times$ Short Term Variance $)$ where $\mathrm{T}$ be the number of sub-periods into which longer period of time can be divided. We considered 5 days as short period and 30 days long period i.e. $\mathrm{T}=6$. When MEC is less than but closer to 1 , it suggests the market is resilient and minimum price volatility is expected. 
Table 1 details descriptive statistics of our data for BSE 500. We observe while on an average return of $0.09 \%$ with slightly above normal distribution kurtosis. We also observe that maximum and minimum values $(0.29 \%$ to $-0.32 \%)$ are evenly distributed. This can be further visualized from Figure 1, making a case for EVT analyses. Additionally, trading probability shows a range of $7 \%$ to $12 \%$ with a high chance of non-normal skewness. As far as MEC is concerned, it has maximum fluctuation and highest skewness and kurtosis. Natural log of total volume seems to be inbound and outside the effect of extreme bound. From Figure 1 we observe the uneven distribution of TP values, especially between $8 \%-9 \%$ and $10 \%-11 \%$, which is very close to its mean value of $9 \%$. Similarly, MEC histogram shows uneven distribution and presence of a long tail. Since bid-ask spread histogram shows an approximately normal distribution, this work which employs EVT has not considered bid-ask spread. Turnover rate series lacks variability required for EVT treatment. We can further analyse TP, MEC and TV which shows a predilection for EVT and justifies our choice for EVT. Also, choice of EVT presents an extra advantage when considering extreme cases like oil-shock, the sub-prime crisis, Brexit or demonetization as EVT treats these events implicitly.

\subsection{Unit Root Tests for Stationarity}

Stationarity tests for time series data are important as these affect both inference procedure and methodological choice. We employ two different tests for stationarity to all four series of returns and liquidity measures: the Augmented Dickey-Fuller (ADF) test [20] and the KPSS test [21]. The work of Kwiatkowski, Phillips, Schmidt and Shin [21] allows a broader definition by considering the stationarity as the null hypothesis. Rejection of null hypothesis is regarded as substantial evidence in favour of a unit root. In this study both the KPSS test and the ADF test are employed to get a holistic picture [22].

\subsection{Extreme Value Theory (EVT)}

In this section, we would briefly discuss mathematics behind the EVT.

$\mathrm{X} 1, \mathrm{X} 2, \cdots, \mathrm{Xn}$ are independent random variables with the same probability distribution, and let $\mathrm{Mn}=\max (\mathrm{X} 1, \cdots, \mathrm{Xn})$. Under certain circumstances, it can be shown that there exist normalizing constants $a_{n}>0, b_{n}$ such that

Table 1. Descriptive statistics: Monthly return and liquidity measures (BSE 500).

\begin{tabular}{ccccccccc}
\hline & Mean & Sd & Median & Trimmed & Min & Max & Skew & Kurtosis \\
\hline Return & 0.01 & 0.08 & 0.02 & 0.02 & -0.32 & 0.29 & -0.6 & 2.85 \\
TP & 0.09 & 0.01 & 0.09 & 0.09 & 0.07 & 0.12 & 0.1 & -0.67 \\
MEC & 0.73 & 1.09 & 0.45 & 0.54 & 0.09 & 11.42 & 6.61 & 56.45 \\
TV & 27.22 & 0.8 & 26.99 & 27.17 & 25.74 & 29.43 & 0.66 & -0.21 \\
\hline
\end{tabular}

Source: Author's computation. 
Histogram of Monthly Return

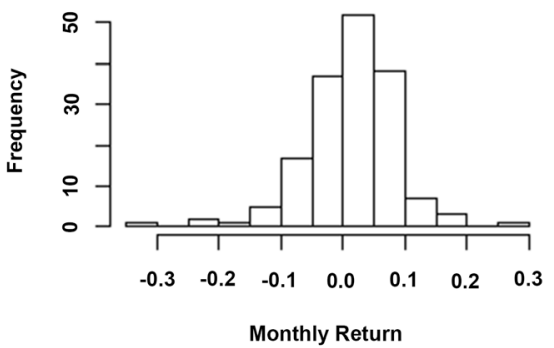

Histogram of Market Efficiency Co-efficient

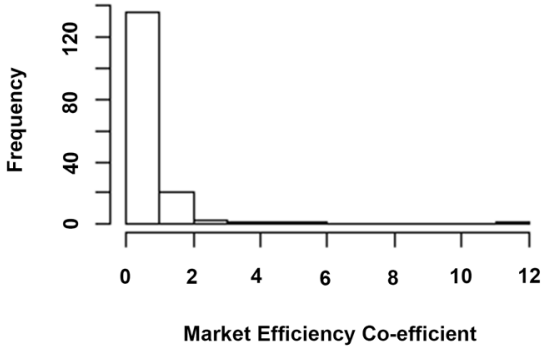

Histogram of Trading Probability

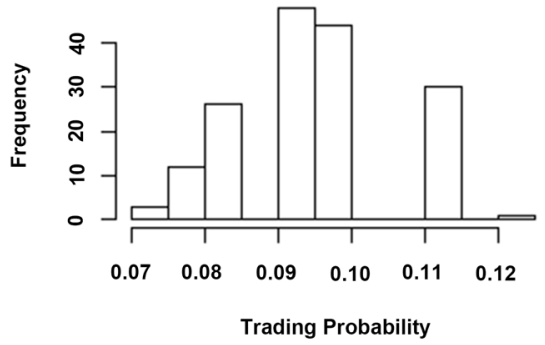

Histogram of lot of Total Volume

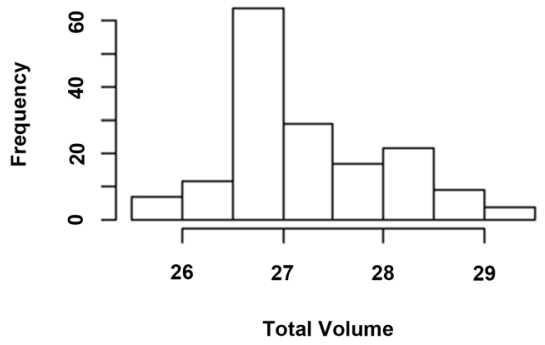

Figure 1. Histogram of return and liquidity measures (BSE 500).

$$
\operatorname{Pr}\left\{\left(M n-b_{n}\right) / a_{n} \leq x\right\}=F\left(a_{n} x+b_{n}\right)^{n} \rightarrow H(x),
$$

where, $H(X)$ represents generalized distribution of $X$.

According to Three-Types-Theorem (Fisher-Tippett, Gnedenko) if non-degenerate $H$ exists, it must be one of three types:

$H(x)=\exp \left(-\mathrm{e}^{-x}\right)$, all $x$ (a Gumbel distribution)

$$
H(x)=0, x<0
$$

$\exp \left(-x^{-\alpha}\right), x>0 \quad$ (a Fr'echet distribution)

$$
H(x)=\exp \left(-|x|^{\alpha}\right), x<0
$$

$1, x>0$ (a Weibull distribution)

In Fr'echet and Weibull, $\alpha$ has to be positive.

The three types may be combined into a single generalized extreme value (GEV) distribution:

$$
\begin{gathered}
H(x)=\exp \left\{-\left(1+\xi *\left(x-\alpha_{n}\right) / \beta_{n}\right)_{+}^{-1 / \xi}\right\}, \\
(y+=\max (y, 0))
\end{gathered}
$$

where $\alpha_{n}$ is a location parameter, $\beta_{n}>0$ is a scale parameter and $\xi$ is a shape parameter. $\xi \rightarrow 0$ corresponds to the Gumbel distribution, $\xi>0$ to the Fr'echet distribution with $\alpha=1 / \xi, \xi<0$ corresponds to the Weibull distribution with $\alpha=$ $-1 / \xi$

$\xi>0$ : "long-tailed" case, $1-F(x) \propto x^{-1 / \xi}$,

$\xi=0$ : "exponential tail"

$\xi<0$ : "short-tailed" case, finite endpoint at $\alpha_{n}-\xi / \beta_{n}$ 


\section{Results and Discussion}

\subsection{Stationarity Test}

A stationarity process of the return series is tested using ADF and KPSS tests. The results of these tests are shown in Table 2.

Table 2 details stationary test results all four-time series (return, TP, MEC, and TV). All of the series are stationary except TV (KPSS Test). We comment that since TV time series is non-stationary in level, hence we would refrain ourselves from making any conclusion based on it.

\subsection{EVT Estimates of Monthly Return}

Table 3 describes the EVT estimates on log return of BSE 500. Based on information criteria (minimum value of AIC and BIC), we found that our model estimates best for monthly aggregate returns. Location parameter changes sign from negative to positive, for the longer time period and scale parameter is less for a greater duration. These two results are intuitive. A shorter duration would usually have lesser extreme values such as maximum and minimum returns on BSE 500.

A higher net return due to the presence of negative location parameter should ideally compensate by higher scale parameter. Therefore, we conclude that a monthly aggregation like monitoring monthly VaR (value at risk) provides better risk parameter. Shape parameter for monthly extreme returns, remains statistically insignificant for monthly and quarterly extreme return values, signifying a Gumbel distribution and estimates better if underlying data likely to follow normal or exponential distribution [23]. Figure 1 shows a histogram of log return which shows a normal distribution kind of distribution, justifying our estimates. We find a significant shape parameter for yearly extreme returns for BSE 500 index, hence Weibull distribution which makes a "Short-Tailed" case with finite endpoint approximately at $0.3 \%\left(\alpha_{n}-\xi / \beta_{n}\right)$, which slightly out of the (but very close) to range $(-0.32 \%$ to $0.29 \%)$ for log returns. We conclude that, compared to a short term monthly investment, a long term investment ought to be less risky. EVT model based on quarterly extreme value perform better than that of yearly aggregation but it remains very risky. This may be because, quarterly results play a big role in an investor's sentiments and consequently it is reflected in the prices.

Table 2. Stationarity test (ADF and KPSS) of returns and liquidity measures,

\begin{tabular}{ccccccc}
\hline & $\begin{array}{c}\text { Augmented Dickey-Fuller Test } \\
\text { (H0: not stationary) }\end{array}$ & & \multicolumn{3}{c}{$\begin{array}{c}\text { KPSS Test for Level Stationarity } \\
\text { (H0: stationary) }\end{array}$} \\
\hline & Dickey-Fuller & Lag order & p-value & KPSS Level & Truncation lag & p-value \\
\hline Return & -5.1634 & 5 & 0.01 & 0.21622 & 2 & 0.1 \\
TP & -5.3383 & 5 & 0.01 & 0.11985 & 2 & 0.1 \\
MEC & -5.399 & 5 & 0.01 & 0.059648 & 2 & 0.1 \\
TV & 5.399 & 5 & 0.01 & 1.1257 & 2 & 0.01 \\
\hline
\end{tabular}


Table 3. EVT Estimates: monthly return.

\begin{tabular}{cccccc}
\hline Aggregation & Location $(\alpha)$ & Scale $(\beta)$ & Shape $(\xi)$ & AIC & BIC \\
\hline \multirow{5}{*}{ Monthly } \\
& -0.01577364 & 0.08238372 & -0.24941479 & -360.7196 & -351.42 \\
& $(0.00684386)$ & $(0.004212016)$ & $(0.019759398)$ & & \\
\hline Quarterly & & & & -159.5598 \\
& 0.04599948 & 0.0469194 & -0.09429101 & -165.5818 & \\
\hline Yearly & $(0.006816561)$ & $(0.004496014)$ & $(0.054302243)$ & & \\
\hline & & & & -29.01732 \\
& 0.0776652 & 0.06905207 & -0.20481165 & -31.14147 & - \\
\hline
\end{tabular}

\subsection{EVT Estimates of TP, MEC and TV}

Table 4 describes the EVT estimates on liquidity measures TP, MEC and natural $\log$ of TV. Based on information criteria (minimum value of AIC and BIC), we found that 1) for TP our model best estimates for monthly aggregate values, 2) for MEC our model estimates best on yearly aggregate values, 3) for TV our model estimates best on yearly aggregate values. Location parameter is close to 0.1 , which is quite high for all time period. This adds a significant liquidity risk. We also found that scale parameter was highest in the case of monthly aggregation, which signifies the presence of extreme cases i.e. minimum trading probability. Extreme values of trading probability on monthly BSE 500 data show a negative shape parameter and hence, a Weibull distribution. This makes a "Short-Tailed" case with finite endpoint approximately at $23.5 \%\left(\alpha_{n}-\xi / \beta_{n}\right)$ which is way out of the observed range (7\% to $12 \%)$ for trading probability. Therefore, it can be said that, during an extreme scenario like the financial crisis, observed TP falls below $9 \%$ against a theoretical possible value of $23.5 \%$ for assets listed on BSE 500, consequently creating a significant liquidity risk in the Indian market. MEC has a positive shape parameter making it an Fr'echet distribution. This distribution makes a "Long-Tailed" case with finite endpoint approximately at $0.4146098\left(\alpha_{n}-\xi / \beta_{n}\right)$.

The endpoint of MEC is well within the range (0.09 to 11.42).We are not making any comments based on EVT estimates of trading volume as this time series has shown the presence of level non-stationarity as shown in Table 2.

From Table 5 and Table 6, we observe the returns sensitivity and extreme range of returns for BSE 500 . We found that, while $10 \%$ of the time, investors' yearly losses won't exceed $4.3 \%$, (12 times 0.3578 ) however, the probability decreases to $0.10 \%$ and $0.01 \%$ for a maximum yearly return of $1.24 \%$ and $2.3 \%$. Similarly, the minimum yearly return should not be less than $3.79 \%$. However, the maximum yearly return would stay below $3.45 \%$, with a probability 0.9957 .

Table 5 and Table 6 also summarize the sensitivity and extreme range of liquidity measures for BSE 500 . We find that with $10 \%$ probability monthly TP won't exceed $9.2 \%$. But, the probabilities decrease to $0.10 \%$ and $0.01 \%$ for a 
Table 4. EVT estimates: Liquidity measures.

\begin{tabular}{|c|c|c|c|c|c|}
\hline & Location $(\alpha)$ & Scale $(\beta)$ & Shape $(\xi)$ & AIC & BIC \\
\hline & \multicolumn{5}{|c|}{ Trading Probability } \\
\hline \multirow[t]{2}{*}{ Monthly } & 0.09063397 & 0.01067649 & -0.25235822 & -1011.7 & -1002.4 \\
\hline & $(0.0009206428)$ & $(0.000656478)$ & $(0.0513461475)$ & & \\
\hline \multirow[t]{2}{*}{ Quarterly } & 0.102197627 & 0.007647448 & -0.276938245 & -375.1813 & -369.1593 \\
\hline & $(0.001132243)$ & $(0.001067715)$ & $(0.112225046)$ & & \\
\hline \multirow[t]{3}{*}{ Yearly } & 0.109539662 & 0.004598719 & -0.178119324 & -112.4289 & -110.3048 \\
\hline & $(0.0012752261)$ & $(0.0006707409)$ & $(0.0959226942)$ & & \\
\hline & \multicolumn{5}{|c|}{ Market Efficiency Co-efficient } \\
\hline \multirow[t]{2}{*}{ Monthly } & 0.3434307 & 0.2408464 & 0.5554789 & 159.3153 & 168.6149 \\
\hline & $(0.0220972)$ & 0.02184602 & $(0.08905541)$ & & \\
\hline \multirow[t]{2}{*}{ Quarterly } & 0.7753343 & 0.3842212 & 0.5746237 & 110.1169 & 116.1389 \\
\hline & $(0.06109291)$ & $(0.06089458)$ & $(0.15749316)$ & & \\
\hline \multirow[t]{3}{*}{ Yearly } & 1.6139904 & 0.7907646 & 0.6071103 & 56.61345 & 58.7376 \\
\hline & $(0.238797)$ & $(0.2441333)$ & $(0.2997652)$ & & \\
\hline & \multicolumn{5}{|c|}{ log Total Volume } \\
\hline \multirow[t]{2}{*}{ Monthly } & 26.865093 & 0.6580961 & -0.0440702 & 379.8588 & 389.1584 \\
\hline & 0.05828496 & 0.04213254 & 0.06219878 & & \\
\hline \multirow[t]{2}{*}{ Quarterly } & 26.97274012 & 0.633656052 & 0.005591595 & 130.3922 & 136.4142 \\
\hline & 0.09777003 & 0.07209921 & 0.11428687 & & \\
\hline \multirow[t]{2}{*}{ Yearly } & 27.13098547 & 0.69807623 & 0.03719912 & 43.36229 & 45.48644 \\
\hline & 0.2037179 & 0.1500206 & 0.2043452 & & \\
\hline
\end{tabular}

Table 5. Extreme liquidity sensitivity.

\begin{tabular}{cccc}
\hline \multicolumn{2}{c}{ Monthly Return } & \multicolumn{2}{c}{ Trading Probability } \\
\hline $\mathrm{p}$ & $\mathrm{Rn}$ & $\mathrm{p}$ & $\mathrm{TP}^{*}$ \\
\hline $10 \%$ & -0.3578 & $10 \%$ & 0.09247 \\
$1 \%$ & -0.0596 & $1 \%$ & 0.10714 \\
$0.10 \%$ & 0.10409 & $0.10 \%$ & 0.11665 \\
$0.01 \%$ & 0.19604 & $0.01 \%$ & 0.12294 \\
\hline Market Efficiency Coefficient & & Total Volume \\
\hline $\mathrm{p}$ & $\mathrm{MEC} *$ & $\mathrm{p}$ & $\mathrm{TV}^{*}$ \\
\hline $10 \%$ & 0.5424079 & $10 \%$ & 25.24361 \\
$1 \%$ & 1.273145 & $1 \%$ & 26.78537 \\
$0.10 \%$ & 4.213816 & $0.10 \%$ & 28.43606 \\
$0.01 \%$ & 16.1077 & $0.01 \%$ & 30.23137 \\
$0.01 \%$ & 16.1077 & $0.01 \%$ & 30.23137 \\
\hline
\end{tabular}


Table 6. Extreme range probability.

\begin{tabular}{ccccc}
\hline & \multicolumn{2}{c}{ Monthly Return } & \multicolumn{2}{c}{ Trading Probability } \\
\hline \multirow{2}{*}{ Max } & Return & Probability & TP & Probability \\
Min & 0.2876259 & $0.00 \%$ & 0.125 & $0.13 \%$ \\
& -0.316158 & $100.00 \%$ & 0.0714 & $98.79 \%$ \\
\hline \multirow{2}{*}{ Max } & MEC & Probability & TV & Probability \\
Min & 11.42403 & $2.88 \%$ & 29.42921 & $4.38 \%$ \\
\hline
\end{tabular}

maximum monthly TP of $11.6 \%$ and $12.3 \%$ respectively. Similarly, minimum TP should not be less than $7.14 \%$. However, maximum TP would stay below $12.5 \%$, with a probability of $98.79 \%$. MEC won't exceed 0.55 with a probability of $10 \%$. But, the probabilities decrease to $0.10 \%$ and $0.01 \%$ for a maximum yearly MEC of 4.2 and 16.1 respectively. Similarly, maximum yearly MEC should not be less than 11.42 with probability less than $3 \%$.

However, yearly MEC would stay above 0.085 . As stated earlier, we avoid making any conclusion based on TV while analyzing sensitivity and extreme range too.

\section{Conclusion and Implication}

Understanding the dynamic nature of liquidity is important. Our work makes an attempt to investigate the presence of liquidity risk in Indian stock market. Our study focuses on liquidity dynamics in case of the extreme events like financial crises. We worked on monthly data of return along with trading probability, market efficiency coefficient, and total volume for a period of July 2002 to Feb 2016 from BSE 500 index. Our data covers pre and post-subprime crisis period, which is crucial for studying the extreme changes in stock market liquidity during that time period. We can conclude the presence of significant liquidity risk in the Indian market. Our EVT estimate justifies the inferences to liquidity risk of Indian stock market. We find that observed TP during crisis time is approximately $1 / 3^{\text {rd }}$ of theoretical possible of $23.5 \%$, making Indian stock market quite illiquid during the time of financial crisis. However, estimates of MEC provide evidence for the resilience of Indian stock market. Therefore, we conclude that Indian stock market is quick to recover from financial shocks. We also found that yearly returns have a range of $-3.8 \%$ to $3.45 \%$ approximately with high probability. Based on this range, we also conclude that Indian market is risky for speculators, however for long-term investment liquidity risk is lower for BSE 500. Our work will help in explaining the seeming vulnerability of Indian stock market and at the same times its resilience, as far stock market liquidity is a concern. Our study can be used to test liquidity pull-back hypothesis, which deals with how demand for liquidity by banks affects the financial market. Cassola, 
Hortacsu and Kasti [24] conclude that liquidity pullback trading is most probably to happen if the link between capital market and the bank is not efficient. Therefore, in the context of Indian capital market, our study of liquidity dynamics might help understand how market participants rebalance portfolios in response to liquidity uncertainty. Our study can be used to propose a prediction model for liquidity risk in the Indian market which would be beneficial for market participants in the Indian market during financial shocks.

\section{Conflicts of Interest}

The authors declare no conflicts of interest regarding the publication of this paper.

\section{References}

[1] Varian, H.R. (1992) Microeconomic Analysis. W. W. Norton \& Company, New York.

[2] Brunnermeier, M.K. and Pedersen, L.H. (2009) Market Liquidity and Funding Liquidity. Review of Financial Studies, 22, 2201-2238. https://doi.org/10.1093/rfs/hhn098

[3] Beck, T. and Levine, R. (2003) Small and Medium Enterprises, Growth, and Poverty: Cross-Country Evidence (Vol. 3178). World Bank Publications.

[4] Acharya, V.V. and Pedersen, L.H. (2005) Asset Pricing with Liquidity Risk. Journal of Financial Economics, 77, 375-410. https://doi.org/10.1016/j.jfineco.2004.06.007

[5] Chordia, T., Roll, R. and Subrahmanyam, A. (2001) Market Liquidity and Trading Activity. The Journal of Finance, 56, 501-530.

https://doi.org/10.1111/0022-1082.00335

[6] Comerton-Forde, C., Hendershott, T., Jones, C.M., Moulton, P.C. and Seasholes, M.S. (2010) Time Variation in Liquidity: The Role of Market-Maker Inventories and Revenues. The Journal of Finance, 65, 295-331. https://doi.org/10.1111/j.1540-6261.2009.01530.x

[7] Chordia, T., Roll, R. and Subrahmanyam, A. (2008) Liquidity and Market Efficiency. Journal of Financial Economics, 87, 249-268. https://doi.org/10.1016/j.jfineco.2007.03.005

[8] Abbassi, P. and Linzert, T. (2012) The Effectiveness of Monetary Policy in Steering Money Market Rates during the Financial Crisis. Journal of Macroeconomics, 34, 945-954. https://doi.org/10.1016/j.jmacro.2012.06.004

[9] Pástor, L. and Stambaugh, R.F. (2003) Liquidity Risk and Expected Stock Returns. Journal of Political economy, 111, 642-685. https://doi.org/10.1086/374184

[10] Marshall, B.R. and Young, M. (2003) Liquidity and Stock Returns in Pure Order-Driven Markets: Evidence from the Australian Stock Market. International Review of Financial Analysis, 12, 173-188. https://doi.org/10.1016/S1057-5219(03)00006-1

[11] Martinez, M.A., Nieto, B., Rubio, G. and Tapia, M. (2005) Asset Pricing and Systematic Liquidity Risk: An Empirical Investigation of the Spanish Stock Market. International Review of Economics and Finance, 14, 81-103. https://doi.org/10.1016/j.iref.2003.12.001

[12] Masulis, R. and Shivakumar, L. (2002) Does Market Structure Affect the Immediacy 
of Stock Price Responses to News? Journal of Financial and Quantitative Analysis, 37, 617-648. https://doi.org/10.2307/3595014

[13] Stoll, H. (2006) Electronic Trading in Stock Markets. Journal of Economic Perspectives, 20, 153-174. https://doi.org/10.1257/089533006776526067

[14] Lesmond, D.A. (2005) Liquidity of Emerging Markets. Journal of Financial Economics, 77, 411-452. https://doi.org/10.1016/j.jfineco.2004.01.005

[15] Jun, S.G., Marathe, A. and Shawky, H.A. (2003) Liquidity and Stock Returns in Emerging Equity Markets. Emerging Markets Review, 4, 1-24. https://doi.org/10.1016/S1566-0141(02)00060-2

[16] Narayan, P.K. and Zheng, X. (2011) The Relationship between Liquidity and Returns on the Chinese Stock Market. Journal of Asian Economics, 22, 259-266. https://doi.org/10.1016/j.asieco.2011.02.005

[17] Bekaert, G., Harvey, C.R. and Lundblad, C. (2007) Liquidity and Expected Returns: Lessons from Emerging Markets. Review of Financial Studies, 20, 1783-1831. https://doi.org/10.1093/rfs/hhm030

[18] Kumar, G. and Misra, A.K. (2015) Closer View at the Stock Market Liquidity: A Literature Review. Asian Journal of Finance \& Accounting, 7, 35-57. https://doi.org/10.5296/ajfa.v7i2.8136

[19] Pasquariello, P. (2007) Imperfect Competition, Information Heterogeneity, and Financial Contagion. Review of Financial Studies, 20, 391-426.

https://doi.org/10.1093/rfs/hhl010

[20] Dickey, D.A. and Fuller, W.A. (1979) Distribution of the Estimators for Autoregressive Time Series with a Unit Root. Journal of the American Statistical Association, 74, 427-431. https://doi.org/10.1080/01621459.1979.10482531

[21] Kwiatkowski, D., Phillips, P.C., Schmidt, P. and Shin, Y. (1992) Testing the Null Hypothesis of Stationarity against the Alternative of a Unit Root: How Sure Are We That Economic Time Series Have a Unit Root? Journal of Econometrics, 54, 159-178. https://doi.org/10.1016/0304-4076(92)90104-Y

[22] Horváth, L., Kokoszka, P. and Rice, G. (2014) Testing Stationarity of Functional Time Series. Journal of Econometrics, 179, 66-82. https://doi.org/10.1016/j.jeconom.2013.11.002

[23] Smith, R.L. (1990) Extreme Value Theory. Handbook of Applicable Mathematics, 7, 437-447.

[24] Cassola, N., Hortaçsu, A. and Kastl, J. (2013) The 2007 Subprime Market Crisis Through the Lens of European Central Bank Auctions for Short-Term Funds. Econometrica, 81, 1309-1345. https://doi.org/10.3982/ECTA9973 